\title{
Resenha do livro FREUD - MAS POR QUE TANTO ÓDI O?
}

\section{Book review WHY SO MUCH HATE?}

\section{Letícia Vier Machado*}

Universidade Estadual de Maringá - UEM, Maringá, Paraná, Brasil

ROUDINESCO, E. Mais pourquoi tant de haine? Paris: Éditions du Seuil, 2010. 88p.

ROUDINESCO, E. Freud - mas por que tanto ódio? Trad. André Telles, rev. técnica Marco Antonio Coutinho Jorge. Rio de Janeiro: Zahar, 2011. 92p.

A obra é uma coletânea de textos organizada pela historiadora da Psicanálise Elisabeth Roudinesco, em parceria com colaboradores como Guillaume Mazeau, Christian Godin, Franck Lelièvre, Pierre Delion e Roland Gori. Este corpo sólido de teóricos franceses, entre professores e pesquisadores, defende a Psicanálise dos rumores que a atacam e descredenciam seu estatuto de ciência psicológica, ao longo dos cinco capítulos do livro, sobretudo na França, e mais intensamente a partir do ano de 2005, com o aparecimento do polêmico "Le livre Noir de la Psychanalyse: vivre, penser et aller mieux sans Freud"1 ${ }^{1}$, que provocou grande revolta e intensos debates entre os psicanalistas franceses.

A publicação é a versão condensada de um trabalho mais extenso, também publicado por Roudinesco em 2005, intitulado Pourquoi tant de haine? Anatomie du « Livre noir de la psychanalyse», co-redigido com Pierre Delion, Roland Gori, Jack Ralite e Jean-Pierre Sueur. O intuito do livro é compreender as razões pelas quais a obra freudiana continua a suscitar acalorados debates, ora apaixonantes, ora odiosos. A coletânea interessa não apenas aos amantes da Psicanálise, estudantes, professores ou psicanalistas, mas a todos aqueles que se propõem a pensar a Psicanálise, adeptos ou não de seu corpus teórico, como uma ciência datada e em movimento, alocada e criticada em contextos sociais, culturais e econômicos diversos. 
Nesse ínterim, na primeira parte da obra a autora apresenta a lente com a qual a obra deve ser lida: a Psicanálise não deve ser analisada como uma teoria imutável. Este seja talvez um dos motivos desencadeantes do ódio que tem pairado sobre a Psicanálise, sobretudo nas duas últimas décadas, somado ao aumento de autores sem tradição acadêmica que se propõem analisá-la, influenciados pelas mídias e, consequentemente, submetidos à pressão mercadológica da produção e da venda massificada de obras acríticas.

Todavia, como revela Roudinesco, o ódio a Freud intensificado nos últimos anos já era manifestado desde seus primeiros escritos. É análogo ao ódio a Darwin. Isso porque Freud trouxe à tona algo de intolerável para a humanidade: a revolução do íntimo e da intimidade, a partir das teorizações sobre o inconsciente e sobre a sexualidade. Além do que, Freud não tratou da sexualidade para reprimi-la ou patologizála, como faziam os psicólogos de sua época: através do uso da palavra, ele liberou o perverso e a mulher histérica de suas aflições (ROUDINESCO, 2010).

No domínio da psiquiatria, Freud introduziu o conceito de "transferência", o que permitiu firmar uma relação de fato com o paciente nas instituições asilares. A partir da década de 1960, com o surgimento da psiquiatria de setor, a revolução da psiquiatria se origina das experiências e inspirações freudianas, que auxiliaram na mudança de postura do cuidador e das técnicas de cuidado (DELION apud ROUDINESCO, 2010).

Sendo assim, os ataques a Freud transcendem sua própria emblemática figura, devem ser lidos e compreendidos como ataques à Psicanálise, à ideia mesma de inconsciente. Porque é somente o inconsciente que pode representar uma força de resistência contra as ilusões do sujeito neoliberal "que gerencia sua existência e seus prazeres como um chefe de empresa"2 (ROUDINESCO, 2010, p. 74).

Mesmo assim, quase um século depois, muitos parecem ignorar a importância de tais avanços. Dentre estes, Roudinesco se refere especificamente a Michel Onfray, teórico articulador da polêmica obra Le crépuscule d'une idole. L'affabulation freudienne ( $O$ crepúsculo de um ídolo. A afabulação freudiana), publicado pela Editora Grasset em 2010. Entretanto, os ataques não provêm somente das linhas de Onfray: a imagem de Sigmund Freud na França tem caricaturado um homem incestuoso, adepto de Hitler e de Mussolini. E, ao ridicularizar Freud, são todos os avanços no domínio do cuidado do sofrimento psíquico que também são colocados em xeque.

Para Michel Onfray, Freud foi um tirano que submeteu as mulheres de sua casa a seus caprichos, homofóbico, falocrata, falsário e ávido por 
dinheiro, cobrando preços "absurdos" em suas sessões. Para Elisabeth Roudinesco, tais críticas relevam um contexto político mais amplo, espelhando o discurso da extrema direita francesa quando equipara a Psicanálise a uma ciência estrangeira, antinacionalista, que parasitaria no Estado-nação francês, concebida por um degenerado oriundo de Viena, uma cidade depravada (ROUDINESCO, 2010, p. 31). Ou ainda, como acrescenta Roland Gori, o livro de Onfray se apresenta como sintoma da nossa civilização, da nossa democracia em crise e da nossa tendência à reificação das consciências onde apenas o que é mercadoria é valorizado (GORI apud ROUDINESCO, 2010).

Interessante é adotar a visão crítica de análise de Roudinesco, historiadora da Psicanálise, para analisar as colocações de Michel Onfray. Afinal, Onfray não é formado em nenhuma tradição de pesquisa histórica, negligencia a realidade do trabalho historiográfico e se apóia principalmente sobre o Livre noir de la psychanalyse para sustentar suas colocações. Este, que reúne trabalhos sob a direção da norte-americana Catherine Meyer, conta com diversos trabalhos da corrente americana revisionista acusando Freud de incestuoso, mentiroso e ávido por dinheiro. Aos psicanalistas, o Livre noir de la psychanalyse reserva acusações como o posicionamento contrário destes à distribuição de seringas às pessoas com AIDS até o apoio à psicanalista Françoise Dolto, falecida em 1988, que teria resultado, desde 2000, no decréscimo da autoridade na escola a partir da idealização da "criança rainha" (ROUDINESCO, 2010, p. 18).

A tese de Onfray é a de que a Psicanálise seria uma planta venenosa que teria florescido numa sociedade decadente (ROUDINESCO, 2010, p. 31). A Psicanálise em si, de acordo com o polêmico autor, corresponde à formação de um complô que consiste em promover o ódio ao pai e a adoração à mãe. Roudinesco, ao longo da obra, não se restringe a contradizer todas as afirmações eloquentes de Onfray, tal como o falso boato de que Freud teria torturado sua filha Anna Freud ao longo da análise que realizara com ela entre os anos de 1918 e 1929, durante a qual teria incitado Anna a se tornar homossexual. Ora, Roudinesco esclarece: a análise de Anna durara quatro anos, e quando ela começara a se conscientizar de sua atração por mulheres, Freud incitou-a a se concentrar no trabalho intelectual (ROUDINESCO, 2010). Além do que, ressalta a historiadora, Freud não considerava a homossexualidade como uma perversão, mas bem ao contrário, era politicamente favorável à emancipação dos homossexuais.

Onfray defende a tese de que Freud, a partir da publicação em 1939 do ensaio Moisés e o monoteísmo ${ }^{3}$, fazendo de Moisés um egípcio e da morte do pai um dos princípios fundadores das sociedades humanas, 
teria também assassinado o pai da Lei judaica, favorecendo o extermínio nazista de seu próprio povo (ROUDINESCO, 2010). Diante do absurdo, Roudinesco questiona: por que a Psicanálise teria então sido banida pelos regimes totalitários ou teocráticos, se, seguindo o raciocínio de Onfray, seus colaboradores corroboravam esses regimes? Afinal, é preciso retomar que a condição para que a Psicanálise se desenvolva é a presença dos Estados de direito, ou seja, das democracias (ROUDINESCO, 2010). Além do que, como esclarece Pierre Delion, são esses mesmos sistemas democráticos que permitem debater sobre a Psicanálise enquanto um sistema psicopatológico e um método terapêutico, desde que o debate seja rigoroso e informado. Caso contrário, caricaturar esse debate é certamente um abuso de poder (DELION apud ROUDINESCO, 2010, p. 80).

Diante de tantas fraudes, Roudinesco e seus colaboradores fazem pensar sobre os motivos que desencadearam o que se poderia chamar de uma "crise da Psicanálise". Contudo, se na teoria a Psicanálise parece atrair cada dia mais afirmações odiosas, a prática revela o contrário: na França, aproximadamente oito milhões de pessoas são tratadas por terapias que derivam da Psicanálise (ROUDINESCO, 2010). I sso nos impulsiona a investigar o fenômeno inserido num contexto social e cultural que impulsionaria, ele mesmo, a proliferação da literatura massificada, não científica e mercadológica, como parecem ter sido as publicações de Michel Onfray.

O livro não deixa escapar uma possível alusão ao fenômeno da medicalização da vida, que vem se exacerbando também no Brasil, e que faz priorizar a concepção unicamente biológica do homem, alocando seu sofrimento e suas angústias em mecanismos cerebrais precisos, passíveis de correção pelos psicofármacos. É inegável que, a partir da Segunda Guerra Mundial, com o advento dos antipsicóticos e a consequente revolução dos psicotrópicos, as instituições asilares foram substituídas pela camisa de força química. O fato representou um progresso para o tratamento das psicoses, certamente, mas não para as neuroses ou para as depressões. No entanto, salienta Roudinesco (2010) que até mesmo diante das psicoses é preciso uma dose de palavra, de psicoterapia. E essa combinação de nanotecnologia farmacológica com psicoterapia custa caro, motivo pelo qual as sociedades ocidentais preferem se conformar com um tratamento farmacológico aparentemente menos custoso, como as terapias da felicidade sob encomenda (ROUDINESCO, 2010).

O expoente máximo desse cientificismo farmacológico é o Manual Diagnóstico e Estatístico de Transtornos Mentais (DSM), atualmente em sua quinta edição, representante de uma ideologia científica que supõe 
que qualquer sofrimento humano deriva de um mecanismo cerebral, excluindo o que a Psicanálise desbravou - a intimidade -, e recusando a subjetividade e a singularidade humanas. Afinal, o sujeito assujeitado do DSM V em nada se assemelha ao sujeito da Psicanálise: aquele é cindido, normalizado e categorizado. Esse movimento do homem que deixa de se tornar sujeito para se tornar objeto é uma ação de mãodupla, já que na nova edição do Manual, lançada em maio de 2013, os próprios sujeitos têm reivindicado a inclusão de patologias e adicções à Internet, esquecendo-se de que para determinar uma adicção é novamente preciso, no mínimo, uma dose anterior de palavra e de escuta (ROUDINESCO, 2010).

E a dose terapêutica de palavra exige que se pense o homem a partir de uma outra racionalidade, que não a racionalidade biomédica e medicalizante. Porque para a Psicanálise, salienta Roudinesco, o homem deriva de uma estrutura biológica, mas também é constituído de mitos, de fantasias e de cultura. A Psicanálise é uma ciência humana, e não biológica: "e se biologizamos as ciências humanas, caímos rapidamente no obscurantismo, ou até mesmo no ocultismo: implantamos causalidades lá onde elas não existem" (ROUDINESCO, 2010, p. 43).

Questionamos, portanto: seria preciso repensar a Psicanálise? É evidente que diante de tantos ataques e do progresso de outras abordagens igualmente válidas, como a cognitiva-comportamental, é preciso que a Psicanálise também evolua. Roudinesco (2010) salienta que práticas retrógradas, como o silêncio do analista durante anos, a despolitização do analista frente a questões sociais e presos a concepções ultrapassadas que condenam práticas como a monoparentalidade ou a homoparentalidade não são mais aceitáveis. O "novo sujeito" que a modernidade e a falência de seus ideais trouxeram consigo produziram também um novo método, uma clínica mutatis mutandis, que não deve cessar de evoluir e de se reinventar com seu sujeito.

Por fim, a obra de Roudinesco faz questionar se as concepções mercadológicas que acompanham a publicação de Onfray não seriam capazes de abolir o senso crítico, representando um perigo do ponto de vista da transmissão dos valores do saber (MAZEAU apud ROUDI NESCO, 2010). Afinal, no contexto de desorientação em que vivemos, na esteira do que o sociólogo Zygmunt Bauman $(2003)^{4}$ denomina de "modernidade líquida", inconstante, sustentamos um profundo desejo de construir nossa história. Entretanto, parafraseando a colocação de Delion, a história que não é eticamente recontada é certamente um abuso de poder. 
Finalizamos a apresentação desse livro necessário e provocador para que se repensem as práticas psicanalíticas contemporâneas fazendo alusão a uma frase de Roland Gori:

Se devêssemos medir o valor da reflexão intelectual e filosófica de uma sociedade à altura dos conceitos que ela constrói e dos comentários críticos das obras que as precederam, poderíamos legitimamente nos inquietar quanto à degradação intelectual da nossa [sociedade] (GORI apud ROUDINESCO, 2010, p. 87-88).

\section{Endereço para correspondência Letícia Vier Machado}

Universidade Estadual de Maringá - Departamento de Psicologia, Bloco 118 - Av. Colombo, 5.790, Jardim Universitário, CEP 87020-900, Maringá-PR, Brasil.

Endereço eletrônico: leticia.psicouem@yahoo.com.br

Recebido em: 16/01/2013

Aceito para publicação em: 08/08/2013

Acompanhamento do processo editorial: Rita Maria Manso de Barros

\section{Notas}

${ }^{1}$ Edição francesa: MEYER, C. (org). Le livre noir de la psychanalyse: vivre, penser et aller mieux sans Freud. Paris: Les Arènes, 2005. Edição brasileira: MEYER, C. (org). O livro negro da Psicanálise: viver e pensar melhor sem Freud. São Paulo: Civilização Brasileira, 2011.

2 Todas as traduções do francês para o português são de responsabilidade da autora.

${ }^{3}$ FREUD, S. Moisés e o monoteísmo, esboço de Psicanálise e outros trabalhos. vol. 23. Rio de Janeiro: Imago, [1937-1939]1996.

${ }^{4}$ BAUMAN, Zygmunt. Modernidade Líquida. Rio de Janeiro: Zahar, 2003. 